\section{AN EXPERIMENT TO ILLUSTRATE THE INDUCTION ON ITSELF OF AN ELECTRIC CURRENT}

$\mathrm{T}^{\mathrm{T}} \mathrm{T}$ is well known that the sudden development of a current in a conductor is opposed by an influence analogous to the inertia of ordinary matter. A powerful movement of electricity cannct be suddenly produced; neither can it be suddenly stopped. One consequence is that a periodic interruption of a circuit in which a constant electromotive force acts is sufficient, when the selfinduction is great, to stop all scnsible current, even although the interruptions themselves may be of very short duration. Before any copious flow can be produced the circuit is broken, and the work has to be begun over again. Whether in any particular case the influence of self-induction is paramount, or not, will depend also on the resistance of the circuit, and on the rapidity of the intermittence. The magnitudes which really come into direct comparison are the interval between the breaks, and the time which would elapse while a current generated in the circuit, and then left to itself, falls to a specific fraction (such as one-half) of its original magnitude. In ordinary cases the duration of transient currents is but a small part of a second of time, so that, in order to bring out the effects of self-induction, the breaks must recur with considerable rapidity.

There is, however, one remarkable exception to the general rule, which occurs when, alongside of the principal coil to which the sluggishness is due, there exists an incependent course along which the electricity can circulate. For instance, suppose that a coil with two wires, such as is often used for electro-magnets, is so arranged that one wire is included in the principal circuit, while the ends of the others are joined. The effect of the second circuit is then to neutralise the self-induction of the first, and so to increase largely the current that passes through it. Let us trace the progress of the phenomenon; supposing that the first circuit has been closed for a sufficient time to allow of the development of the full current which can be excited by the actual electromotive force.

The moment the rupture is complete, the current in the first wire must stop, but another of the same magnitude and direction is at once developed in the neighbouring circuit. In fact, in virtue of its inertia, the electrical motion $t \in n d s$ to continue with as little change as possible, a result which is attained in great degree by the formation of the second current to fill the place of the first. In a short time the induced current would diminish and become insensible under the operation of resistance (analogous to ordinary friction); but we are supposing that before this takes place to any considerable extent the contact is renewed, and the electromotive force arain begins, in the first circuit, to push the electricity on. It is now that the peculiarity of the arrangement manifests itself. The current instantly transfers itself back again to the first circuit, which thus, without any delay, has the advantage of the full current which the electromotive force can sustain. If it had not been for the second circuit and its current, the development in the first would only bave been gradual, and by supposition so slow that it would be checked by another interruption before any considerable progress could be made. In short, the selfinduction of the principal circuit is virtually destroyed.*

In my experiment the principal circuit consisted of a Smee cell and one wire of a coil belonging to a large electro-magnet, and which I may call A. The interrupter was a tuning-fork, arranged after Helmholtz, and set into regular vibrations of about 128 per second by an independent current and battery. The fork itself was forged

* Mathematicians familiar with the theory of electricity will follow this by putting the three induction co-efficients (in Maxwell's notation, L, M, N) equal, and the resistance of the second circuit, $S$, equal to zero. by the village blacksmith, and the whole affair was home-made. Across one prong was placed a sort of rider of copper wire, dipping on either side into a mercury cup, and so arranged that during the vibration its ends should enter and leave the mercury, thereby establishing and interrupting the continuity of the circuit. The current was measured by means of a short wire galvarometer whose electrodes were connected with two neighbouring points of the circuit in such a manner that a small but constant proportion of the entire current passed through the instrument. The second wire of the coil, $A_{2}$, which is similar to the first and put on with it, formed the second circuit, when its ends were joined by a short wire. In order to increase at pleasure the effects of induction, iron wires or rods of about a quarter of an inch in diameter were provided, whose insertion in the coil materially increased the decisiveness of the result.

In the first place, the deflection produced on the galvanometer when the circuit was permanently completed was $58^{\circ}$, which fell to $39^{\circ}$ when the interrupter was at work, the circuit of $A_{2}$ being open, and without iron. On closing $A_{2}$ the defiection rose to $46^{\circ} . A_{2}$ was again opened, and one iron wire introdiced, which gave $30^{\circ}$. Two wires"gave $25^{\circ}$, while the introduction of thirty reduced the deflection to $12^{\circ}$. Again closing $A_{2}$, the reading was $43^{\circ}$, raised to $44^{\circ}$ only by the removal of the iron. It was clear that the second circuit almost secured the first from the influence of induction, which otherwise greatly reduced the electrical circulation. I may add that the arrangement was very efficient, the galvanometer needle remaining perfectly steady, so that the readings could be taken with ease and accuracy.

Another experiment made at the same time (about two years ago) may be noticed, if only for its contrast with the preceding. The coil $\mathrm{A}$, being removed from the main circuit, was included in the branch with the galvanometer, as shown in the figure. Here neither the insertion of

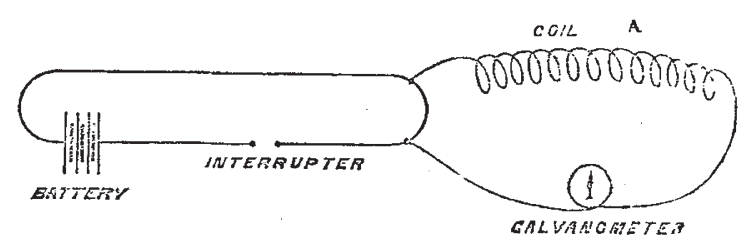

iron nor the closing of $A_{2}$ made any difference; the circuit containing the coil remaining always closed, whatever might be the condition of the other. In such circumstances the average current indicated by the galvanometer is independent of the self-induction of the coil, varying only with the resistance in the branch, and with the azierage difference of potential at the points of derivation.

J. W. STRUTT

\section{SOME REMARKS ON THE HABITS OF SOME CEYLON ANIMALS, AND NOTES ON METHODS FOR KEEPING THEM ALIVE IN CONFINEMENT}

$A$ FTER my duties as member of the Eclipse Expedition were over, I spent some time in Ceylon collecting natural history specimens for the Oxford Museum. Besides preserving a large series of animals in solutions, I obtained through the kindness of my friend, Mr. G. H. K. Thwaites, F.R.S , of Peradeniya, whose kind hospitality I enjoyed, and to whom I am indebted for nearly all my best specimens and information concerning them, various living examples of the Ceylon fauna, and I kept them with more or less success in confinement. Some notes 
as to my experiences with regaril to them may be of interest to the readers of NATURE.

Passerita mycterizans. - A brilliant emerald green tree snake, with horizontal pupil. I obtained a fine specimen about $4 \frac{1}{2} \mathrm{ft}$. long. I put him in a small wooden box with wire-gauze cover. As usual with this species, he would not feed, but drank frequently with great eagerness. Snakes often die in confinement for want of water. In the case of tropical snakes, it should not be forgotten that the water must be warmed as soon as colder latitudes are reached. This snake is now in the Regent's Park Zoological Gardens, and has now been two months without food. The keeper tells me that a specimen formerly in the Gardens lived six months without eating.*

Lyriocephalus scutatus. - These lizards live in large numbers in the Royal Botanic Gardens, Peradeniya, frequenting the moist shady. banks of the Mahawillaganga, which bounds the Gardens in one direction. The animals sit all day on tree trunks, with their head uppermost. They can run very fast, but are easily caught, as is the case with most lizards, with a slip noose of palm fibre. They allow the noose to be put over their heads with the greatest ease. When first caught they are very fierce, and display their array of sharp teeth and bright scarlet mouths whenever a finger is moved near them, and they bite hard whenever they get a chance, holding like bulldogs, as I often experienced to my cost when feeding them. I could not get them to feed themselves either whilst in Ceylon or on the voyage home. I therefore fed them by hand, opening their mouths forcibly by pulling on the pouch-skin and pushing worms down their throats. After a time they chewed and swallowed the worms readily on their being put in their mouths. I also poured water down their throats. I kept a stock of worms alive at the bottom of the cage in moist earth. Kelaart, in his Nat. Hist. of Ceylon, says that Lyriocephalus takes boiled rice freely in confinement ; and Dr. Günther, "Indian Reports," p. 129, quotes him to that effect. I think this must be an entirely erroneous statement. I forced rice down the animals' throats, but they never seemed to relish it, and they never touched it of themselves whilst under my care, nor have they done so since they have been in the Regent's Park Gardens. The lizards are remarkable for their curious lyre-shaped heads, and the large knobs on the ends of the snouts of the adults. In young specimens the knob is very little developed. It is present in both sexes. The lizards change colour with great rapidity when excited, even whilst held in the hand. They were brought home in a tall wooden cage, by the advice of $\mathrm{Mr}$. Thwaites so arranged that they could rest in their usual vertical position on some rough bark nailed on to the sides of the cage for the purpose. They clung on to these supports and the perforated zinc front during all the voyage home, and in their den in the reptile house in the Gardens they are always to be seen clinging to the branches head uppermost. The cage was kept on the voyage from Alexandria to Southampton in the engineroom of the P. and O. steamship Mooltan, as was also the box with the tree snake, and both were taken up to town from thence wrapped in a double blanket. Four of the lizards are now alive in the Regent's Park Gardens. They are still fed by hand, but one has been seen by the keeper to help himself to worms. Some time ago an attempt was made by $\mathrm{Mr}$. Houldsworth to bring Lyriocephali home alive, but his specimens unluckily died in the Channel. Perhaps they were not hand-fed.

The ground in Ceylon swarms with burrowing reptiles of various kinds, and Mr. Thwaites's coolies used to dig me up as many as twenty in an afternoon. They all came from the moist river bank. Most abundant in the various lots I received was always Nessia monodactyla, a lizard which, having taken to underground habits, has become

* Since the above was written this snake has not only swallowed a young bird, but has also attempted to swallow another snake of a different species confined in the same cage. snake-like, and retains the merest rudiments of both its limbs. I kept all my underground reptiles in damp moss in-joints of the gigantic bamboo. The Nessias move with great agility through the moss, and lived well in confine. ment. I hardly ever saw one in which the tail was not a reproduction.

Rhinophis Bythii.-These were not half so nimble as the Nessias, and seemed rather more delicate.

ryphlops braminus. - These small blind-worm-like snakes were not so abundant as the Rhinophida or Nessias, but there were generally one or two in each batch. They are very active, escape through the smallest crack, and are with difficulty retained in the hand. I kept the Nessias, Rhinophida, and Typhlopida together in a bamboo. I gave them earth-worms. The worms disappeared, but also did the Typhlopidce. These could not have escaped; but were probably eaten by the Rhinophida.

Cacilians.-Epicrium glutinosum.-I had only four specimens brought me of Cacilia. They came from the same bank as the Nessias, \&c. They move along the ground with a slow helpless wriggling motion, feeling their way with their remarkable exsertile labial tentacles. These tentacles are in constant motion, being alternately protruded and retracted. They are evidently the animals great stand-by in the special-sense way, and probably contain interesting terminal nervous organs. The Cæcilians have a certain amount of prehensile power in their tails. When placed in water they are very active, moving like eels, and seeming to enjoy themselves thoroughly. I kept them in moss in a bamboo, and put worms with them, which disappeared in no small quantities.

Mygale marmorata.-This spider, a full-sized one, ate clean up five large cockroaches in the first two nights I had it. A day later it cast up a large pellet, composed of the chitinous skins of its victims, just as a rapacious bird casts up feather pellets. It spun a small quantity of irregular web against the side of its cage. As far as I could observe, the spider did not feed again in the three weeks during which I kept it alive.

Scorpion hubrostonos. - These large black scorpions I could not get to feed at all, though I tried them with insects and raw meat.

Land Planarians.-Bipalium Diana, B. Proserpina, B. Phobe, and Rhynchodemus Nietneri-I obtained numbers of specimens of these huge Planarians, some as much as eight inches long. I tried several times to keep them alive amongst moist leaves, but unfortunately failed. They never lived longer than four or five days, then appeared to deliquesce into a slimy mass of corruption.* The slime of these Planarians is so tough that they can suspend themselves by a thread formed of it, and I have several times had them lower themselves thus from my hand to a table by means of a thread six or seven inches long. I have only seen Bipalium Diana and Proserpina do this, not Rhynchodemus. The cellar slug, Limax agrestis, uses a mucous thread for suspension in a similar manner (Binney's "Terrestrial and Air-breathing Molluscs of the United States," vol. ii. p. 39). When in motion, the Bipaliums throw out a series of short tentacular-like papillæ from the front edge of their semicircular anterior extremity. I had all the animals I have mentioned, except the Planarians, alive as far as Suez, but unfortunately they were all killed by the intense cold of the night journey across the desert to Alexandria, except the Lyriocephali and Passeritia, which I took in the carriage with me and kept warm. The train was so crowded that I was obliged to put the rest in the van. I especially grieved over the loss of the Cæcilians; they were especially well and healthy, and I feel certain I should have got them home alive had it not been for this mishap. I had hoped to be able to get them to breed, and to watch their development.

H. N. MOSELEY

* Mr. Darwin had much better success with the South American Land Planarians,-- "Darwin's Journal of Researches," I860 Edition, p. 27. 